Supplement of

\title{
A Parameterization of Sub-grid Topographical Effects on Solar Radiation in the E3SM Land Model (Version 1.0): Implementation and Evaluation Over the Tibetan Plateau
}

Dalei Hao ${ }^{1}$, Gautam Bisht ${ }^{1}, \mathrm{Yu} \mathrm{Gu}^{2}$, Wei-Liang Lee ${ }^{3}$, Kuo-Nan Liou ${ }^{2}$ and L. Ruby Leung ${ }^{1}$

${ }^{1}$ Atmospheric Sciences and Global Change Division, Pacific Northwest National Laboratory, Richland, WA, USA

${ }^{2}$ Joint Institute for Regional Earth System Science and Engineering and Department of Atmospheric and Oceanic Sciences, University of California, Los Angeles, CA, USA

${ }^{3}$ Research Center for Environmental Changes, Academia Sinica, Taipei, Taiwan

Correspondence to: Dalei Hao (dalei.hao@pnnl.gov) 
(a) $\sin (\alpha) \cdot \cos (\beta)$

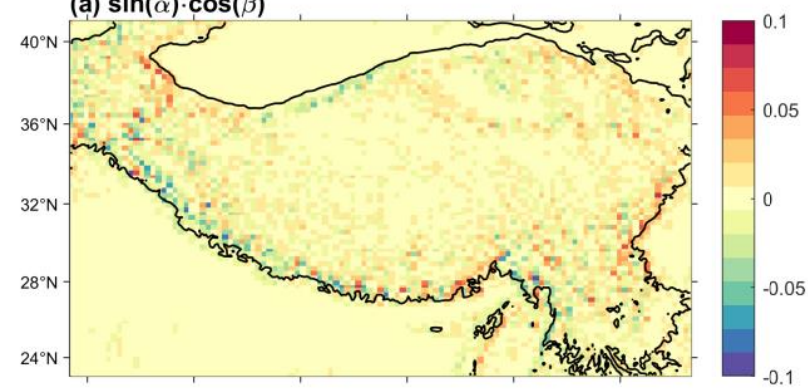

(c) Sky view factor

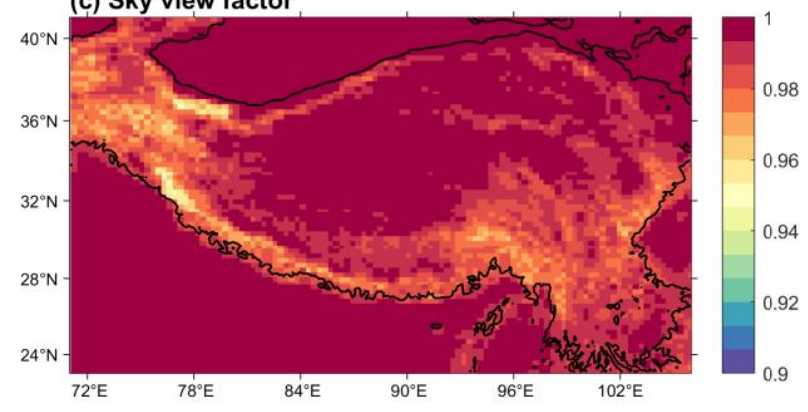

(b) $\sin (\alpha) \cdot \sin (\beta)$

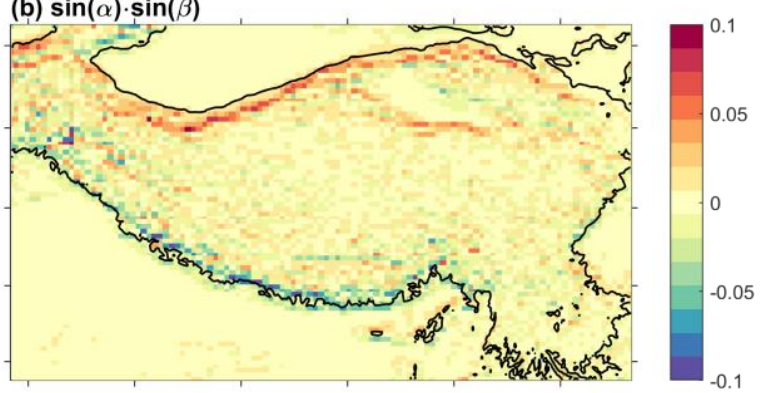

(d) Terrain configuration factor

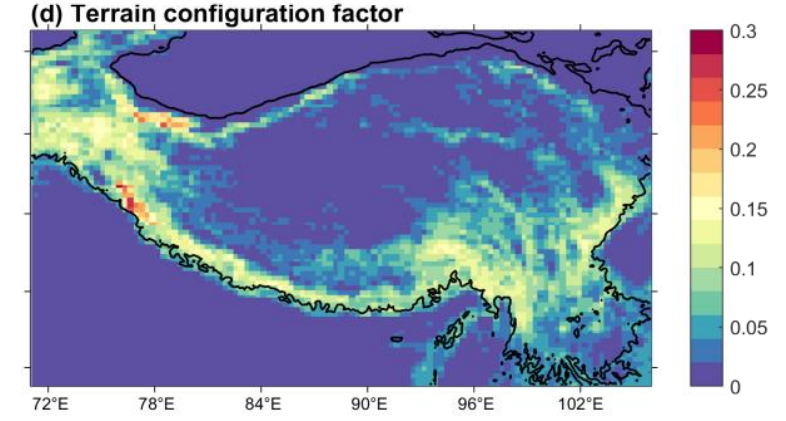

Figure S1. Spatial distributions of grid averaged values of $\sin (\alpha) \cdot \cos (\beta)(a), \sin (\alpha) \cdot \sin (\beta)(b)$, sky view factor (c) and terrain configuration factor (d) derived from $90 \mathrm{~m}$ DEM at $0.125^{\circ} \times 0.125^{\circ}$ spatial resolution over the TP. 
(a) $\mathrm{r} 0125$

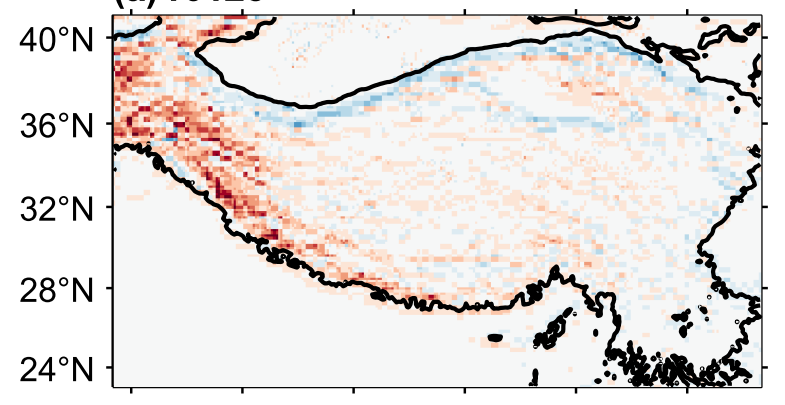

(c) $\mathrm{r} 05$

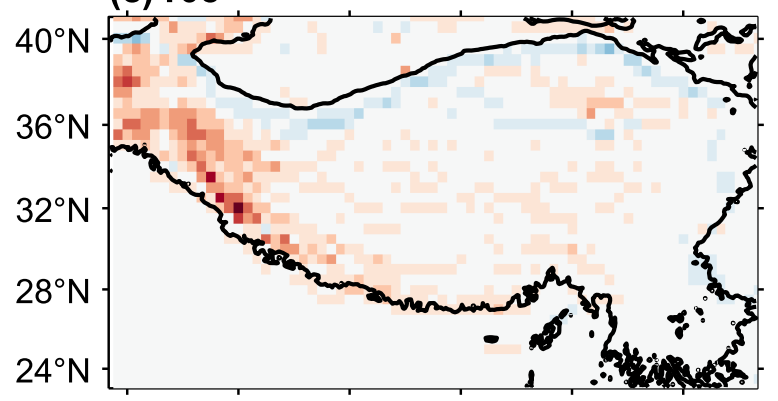

(e) f19

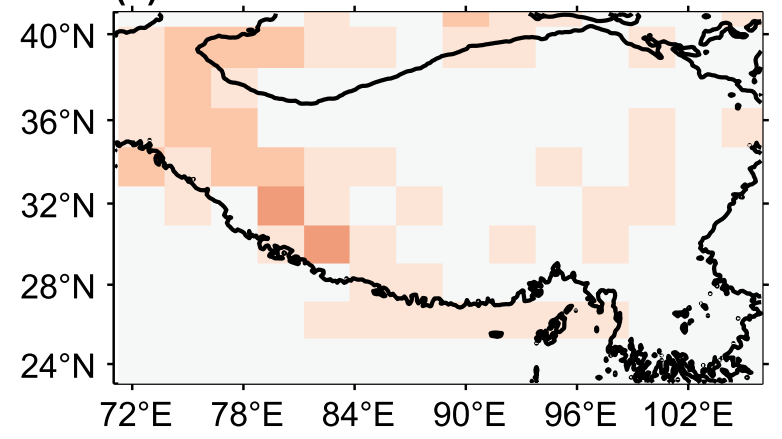

(b) r025

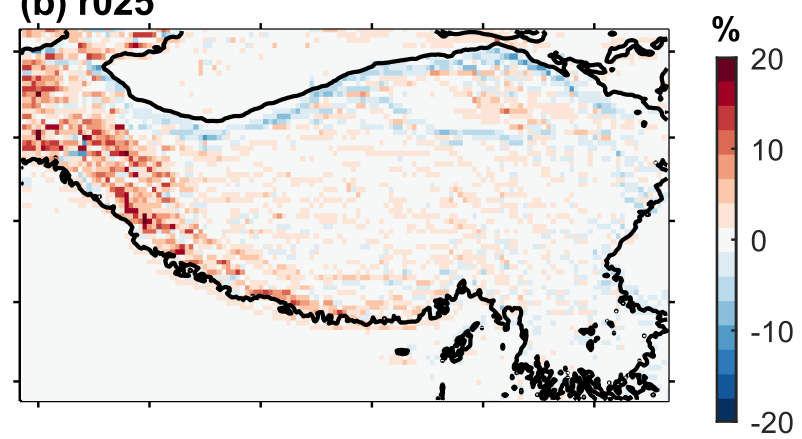

(d) f09

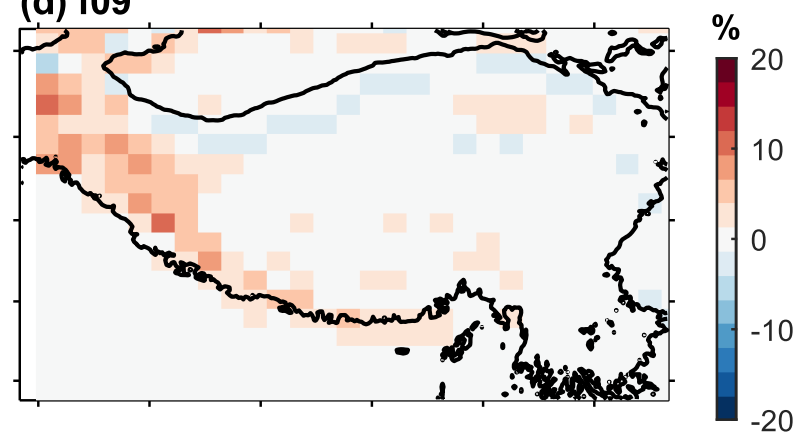

(f)

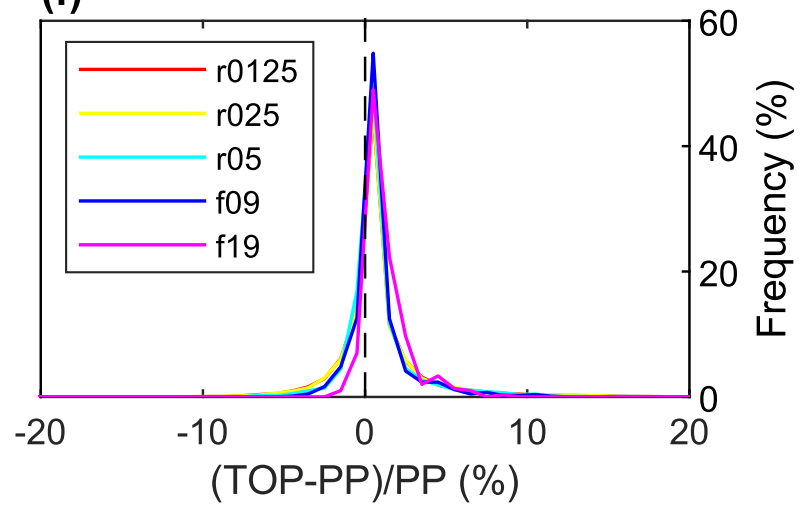

Figure S2. The relative differences of net solar radiation between TOP and PP in winter at different spatial scales (a-e) and the statistical histogram of their frequent distributions (f). 
(a) r0125

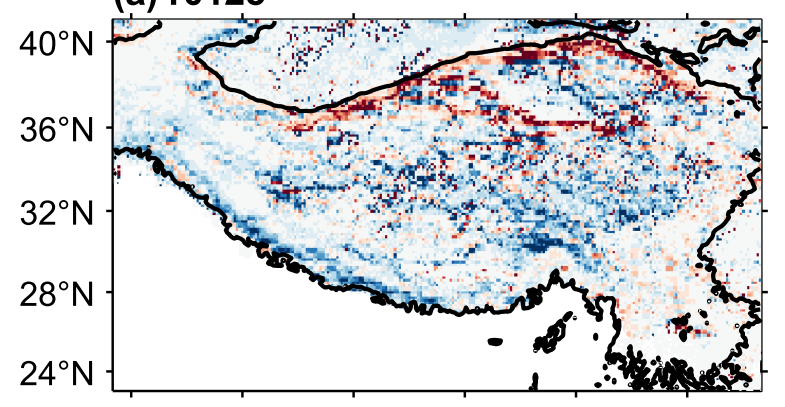

(c) $\mathrm{r} 05$

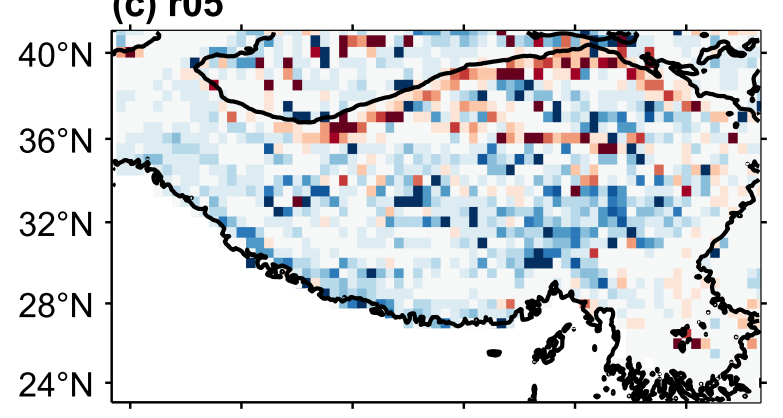

(e) $f 19$

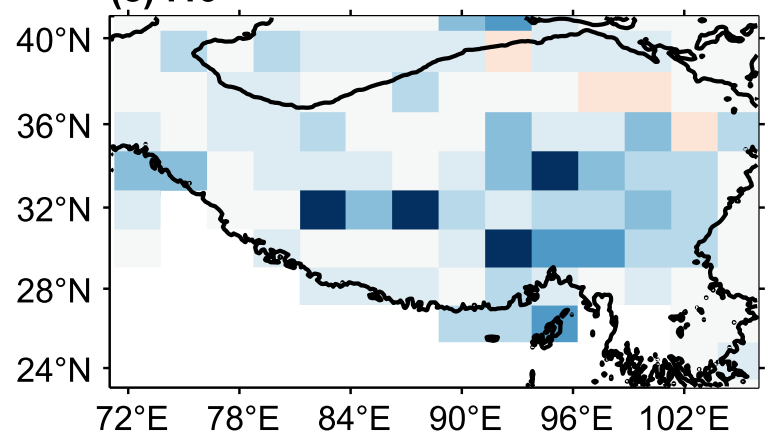

(b) r025

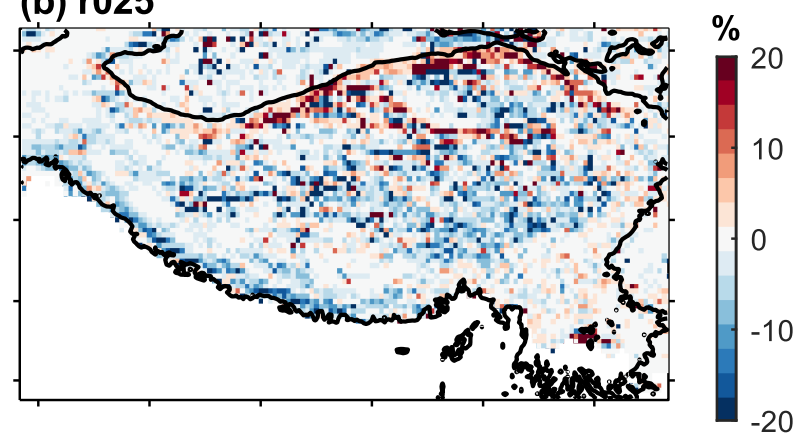

(d) f09

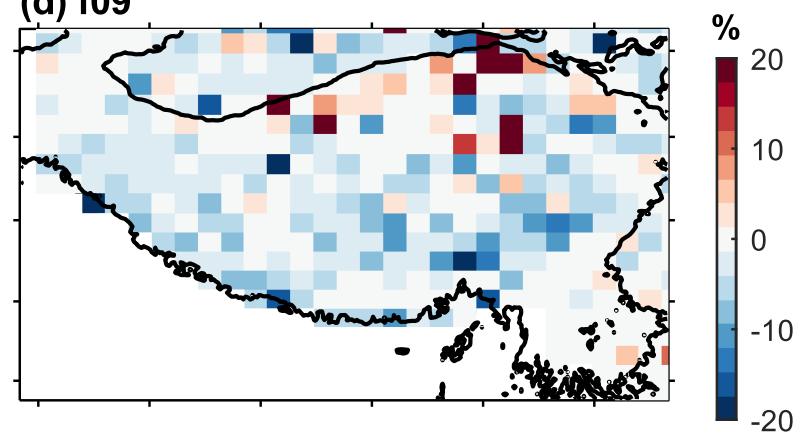

(f)

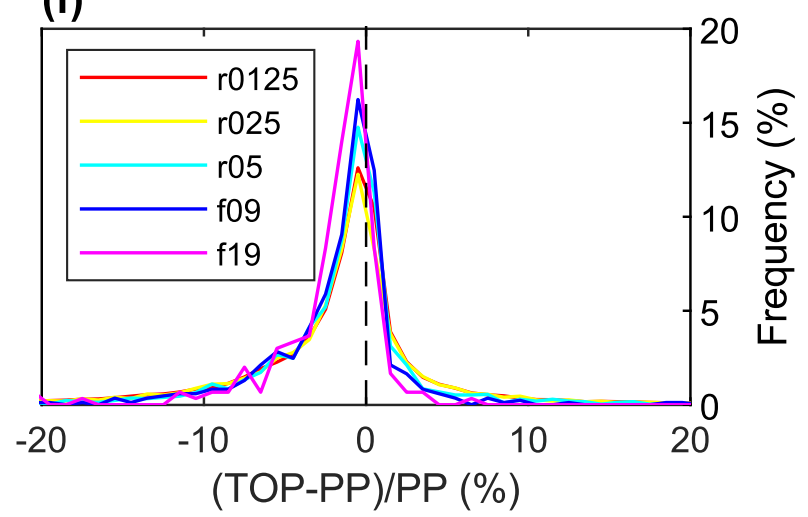

Figure S3. Same as Figure S2 except for snow cover fraction. 
(a) r0125

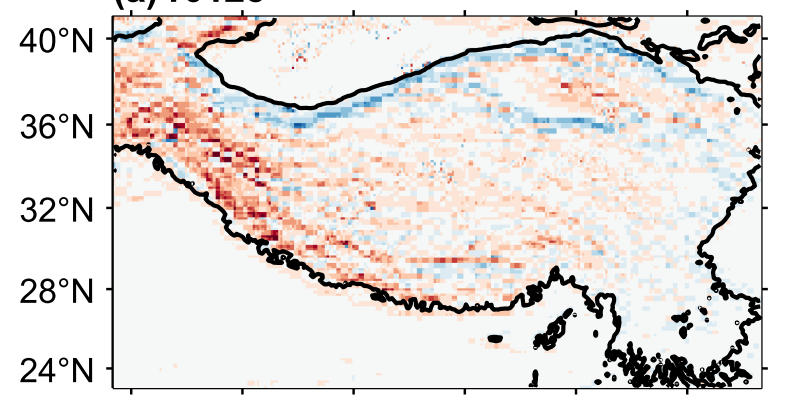

(c) $r 05$

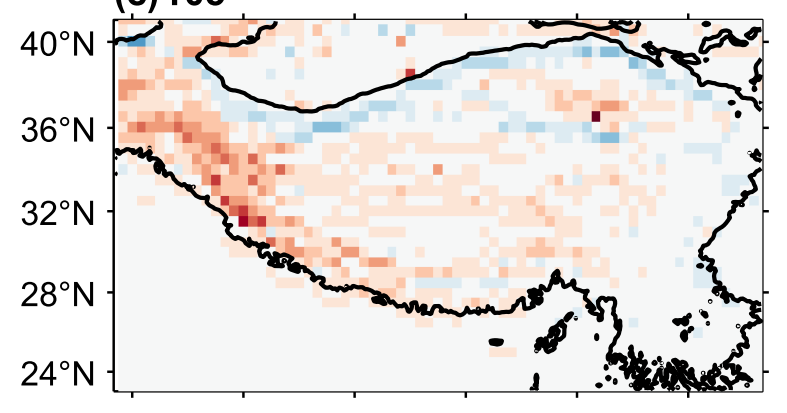

(e) f19

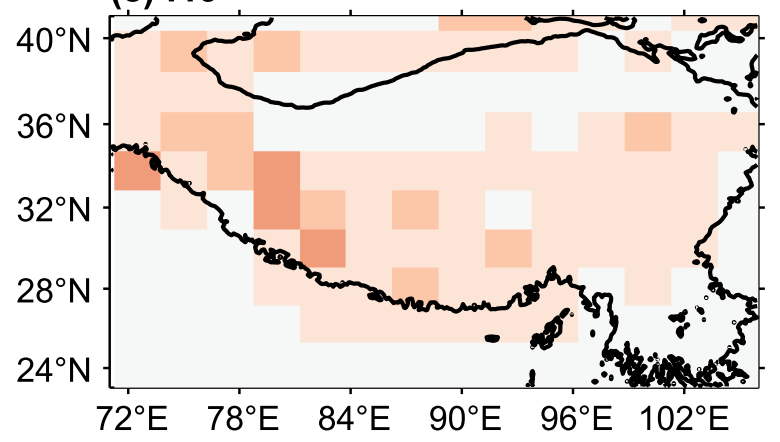

(b) r025

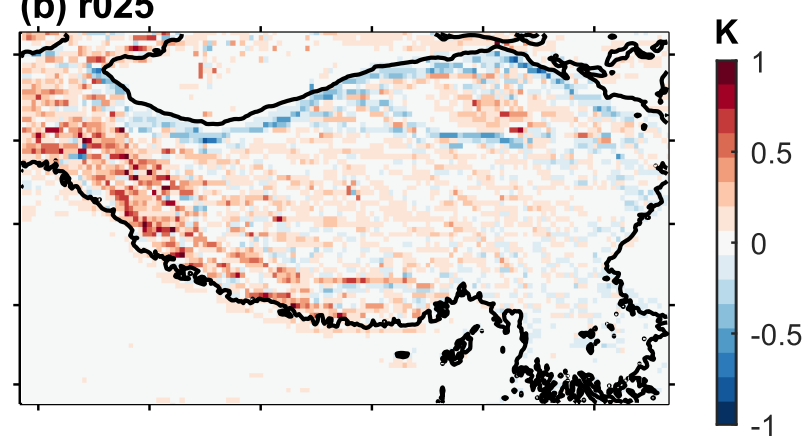

(d) f09

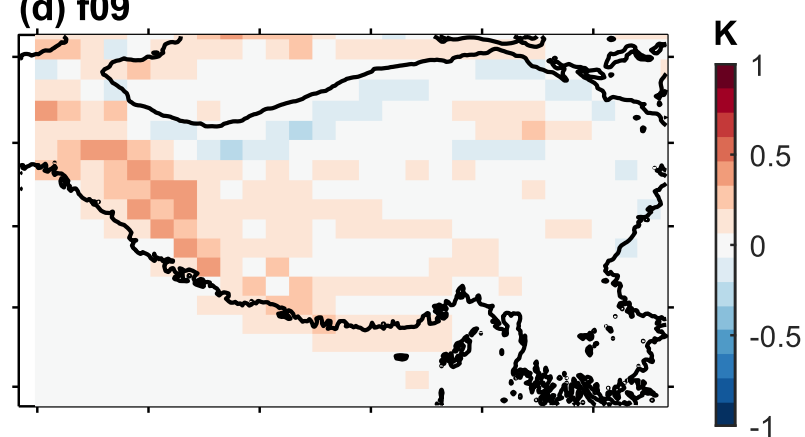

(f)

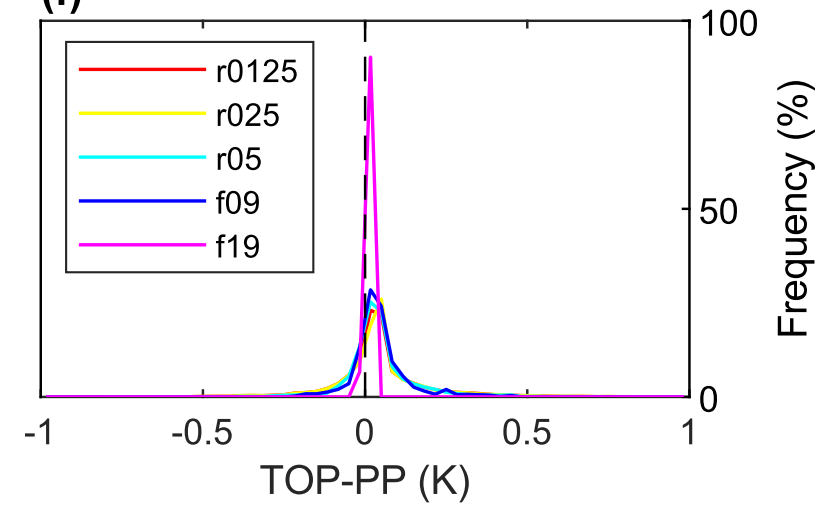

Figure S4. Same as Figure S2 except for the absolute differences of surface temperature. 
(a) r0125

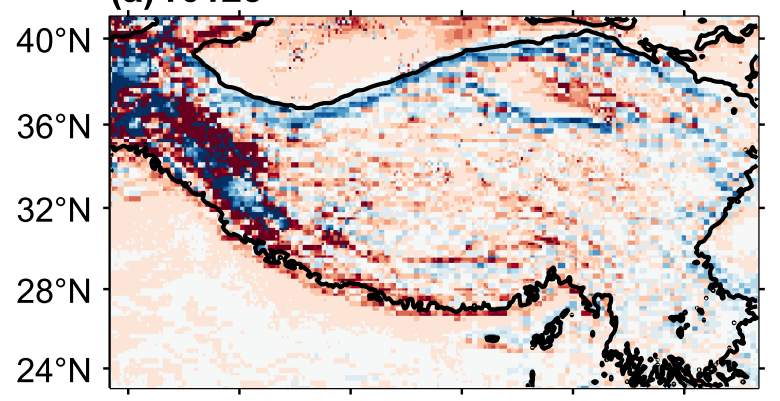

(c) $\mathrm{r} 05$

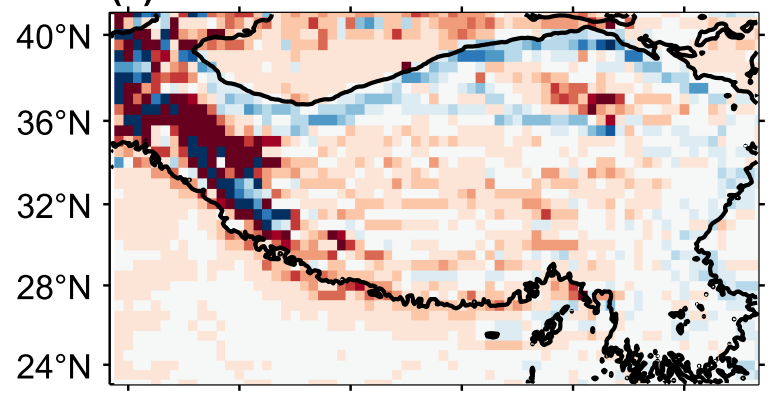

(e) f19

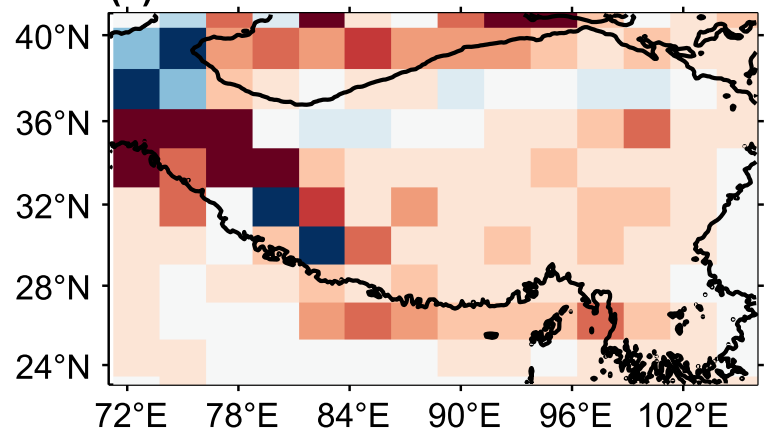

(b) $\mathrm{r} 025$
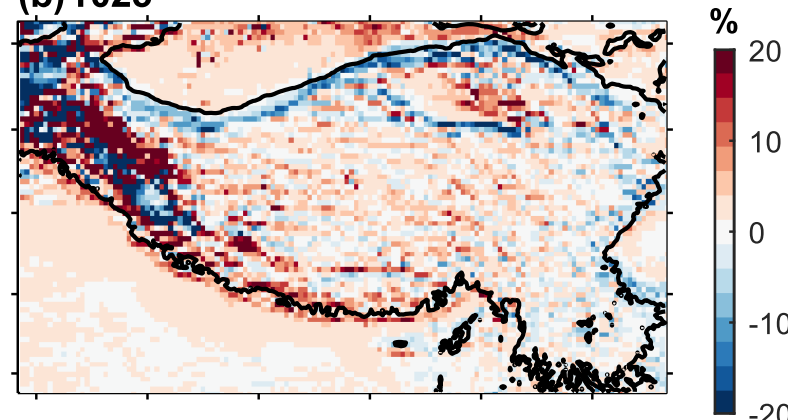

(d) $f 09$

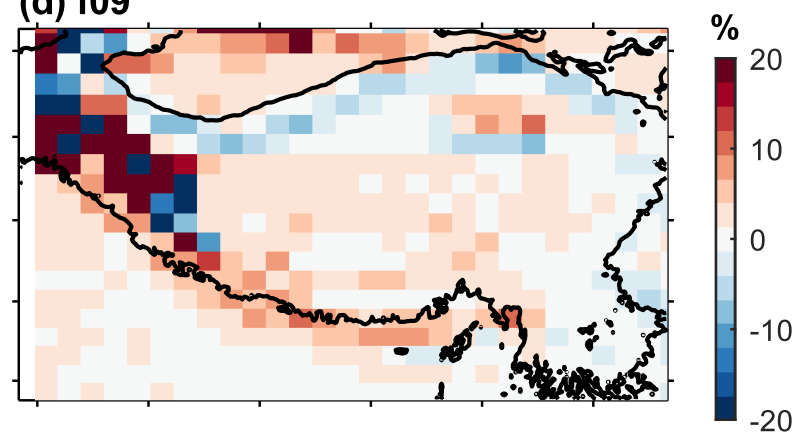

(f)

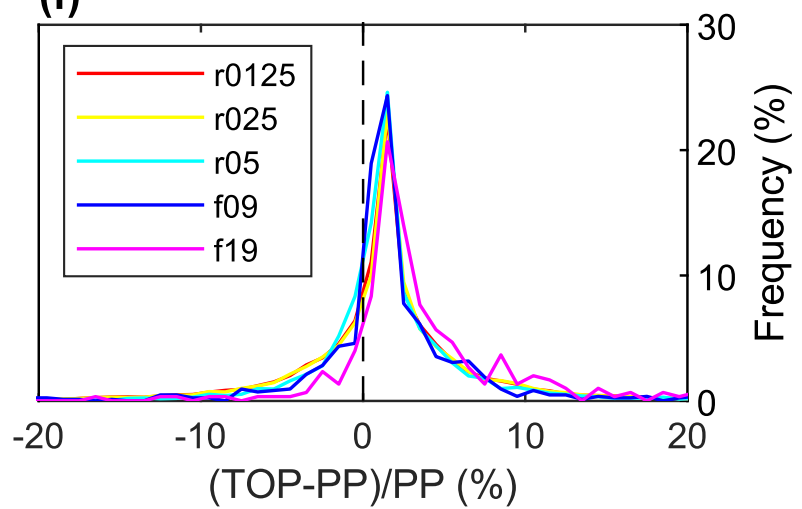

Figure S5. Same as Figure S2 except for sensible heat flux. 
(a) r0125

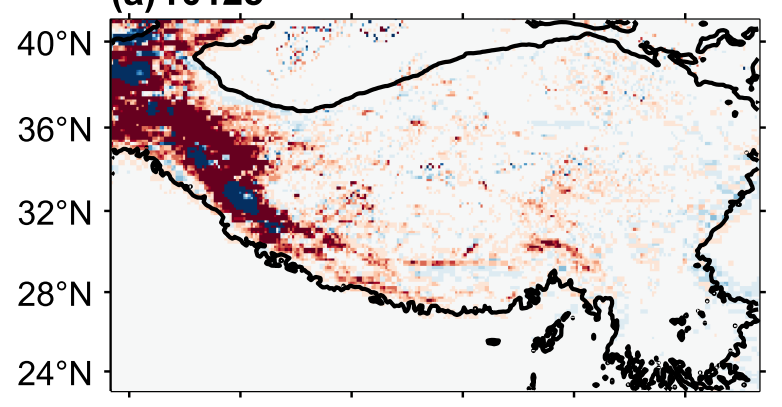

(c) r05

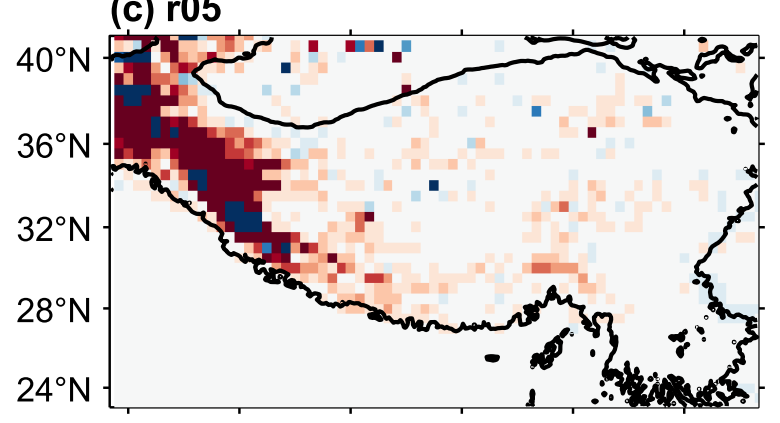

(e) $f 19$

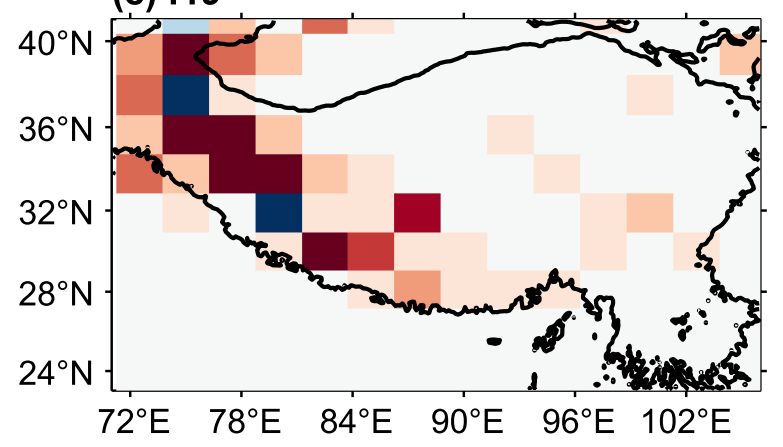

(b) $\mathrm{r} 025$

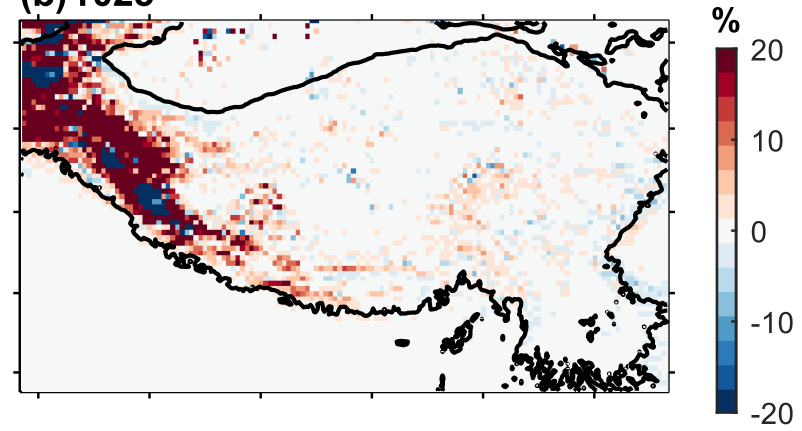

(d) $f 09$

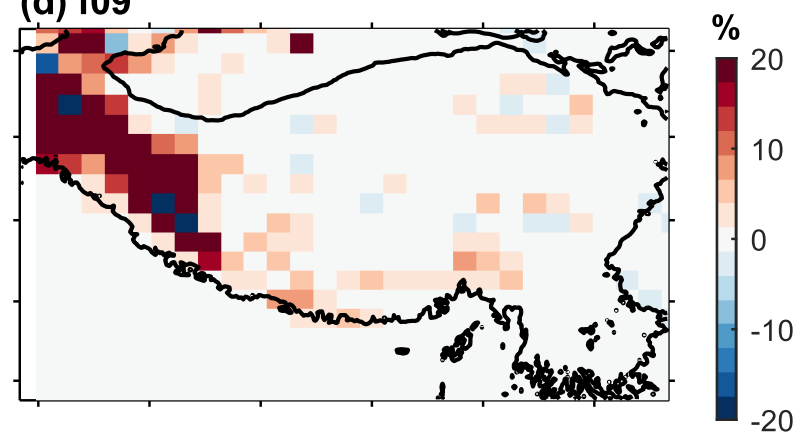

(f)

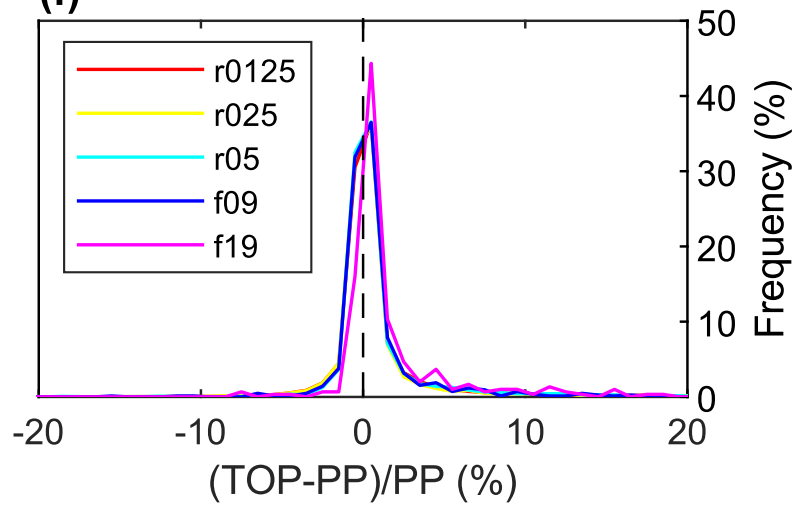

Figure S6. Same as Figure S2 except for latent heat flux. 

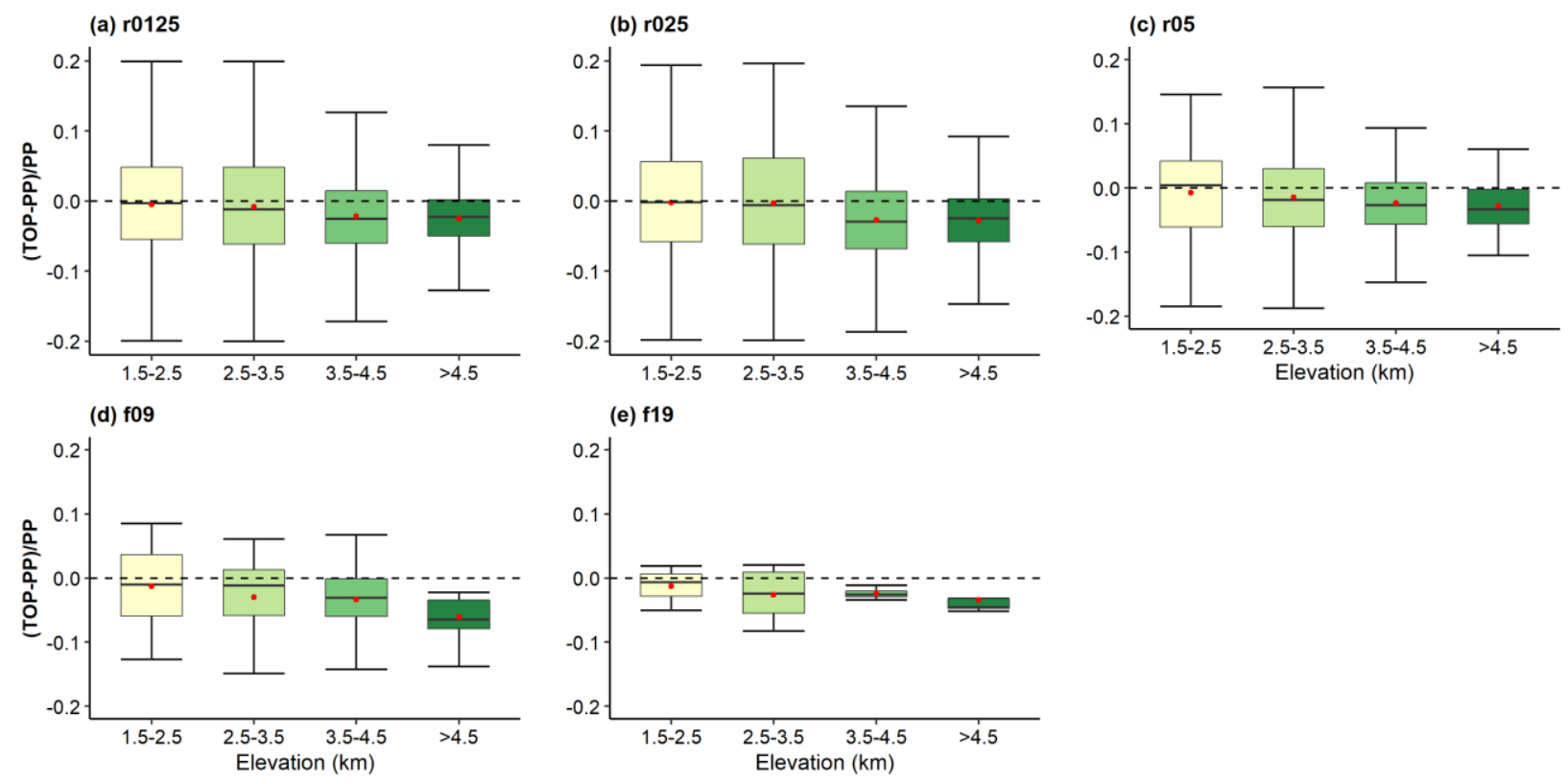

Figure S7. Boxplots of the relative differences of land surface albedo between TOP and PP in winter at different spatial scales and different elevation bands. Red points represent the mean values. 


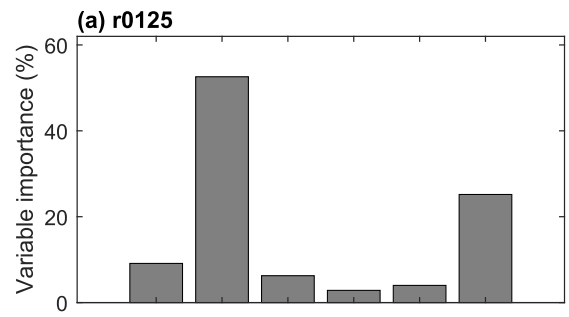

(b) r025

(c) $r 05$

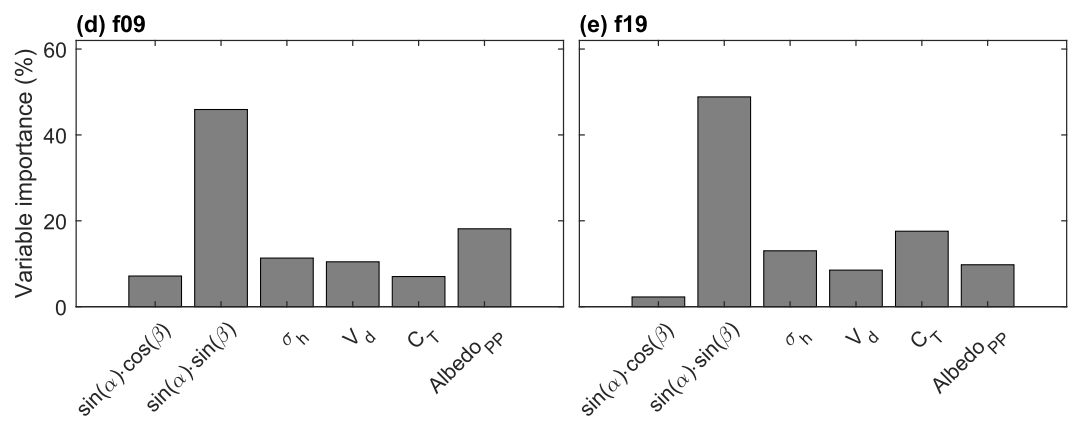

Figure S8. Sensitivity of the relative difference of land surface albedo between TOP and PP to topographic factors in winter at different spatial scales. 